\section{FRI0641-HPR INTERSTITIAL LUNG DISEASE AS INITIAL MANIFESTATION OF SYSTEMIC AUTOIMMUNE RHEUMATIC DISEASES IN A MONOCENTRIC COHORT: THE IMPORTANCE OF A MULTIDISCIPLINARY APPROACH}

F. Bozzao ${ }^{1}$, P. Tomietto ${ }^{2}$, I. Prearo ${ }^{3}$, S. M. G. Pirronello ${ }^{4}$, O. Magazzino5, M. Kodric ${ }^{6}$, R. Della Porta ${ }^{6}$, R. Cifaldi ${ }^{6}$, E. Baratella ${ }^{7}$, F. Fischetti ${ }^{2}$,

M. Confalonieri', B. Fabris ${ }^{2}{ }^{1}$ University of Trieste, Internal Medicine, Trieste, Italy; ${ }^{2}$ Azienda Sanitaria Universitaria Giuliano Isontina, Internal Medicine, Trieste, Italy; ${ }^{3}$ University Hospital LMU Munich, Medical Clinic and Policlinic IV, Munich, Germany; ${ }^{4}$ Azienda Ospedaliera Cannizzaro, Emergency Department, Catania, Italy; ${ }^{1}$ University of Trieste, Internal Medicine, Trieste, Italy; ${ }^{6}$ Azienda Sanitaria Universitaria Giuliano Isontina, Cardiothoracovascular Department, Trieste, Italy ${ }^{7}$ Azienda Sanitaria Universitaria Giuliano Isontina, Radiology Department, Trieste, Italy

Background: Interstitial lung disease (ILD) can be the first manifestation of connective tissue disease (CTD) and rheumatoid arthritis (RA). Pulmonologists are usually the first referral in these patients.

Objectives: To determine: 1) the prevalence of ILD as initial manifestation of CTD or RA 2) clinical characteristics of such patients.

Methods: From a database of consecutive patients with CTD or RA referred to our academic hospital from 2009 and 2017, we selected all the patients with ILD as initial manifestation of the disease. Periodic multidisciplinary evaluations were performed during a median follow-up of 48 (35-50) months.

Results: 1) Fifty-four of the 427 patients with CTD or RA (12.6\%) had ILD as initial manifestation (mean age: $63.9 \pm 12.9 \mathrm{yrs}$, F/M ratio: 20/34). Autoimmune myositis was diagnosed in $16 / 54$ patients $(29.6 \%)$, systemic sclerosis in 11 patients $(20.4 \%)$, RA in 9 patients $(16.7 \%)$, Sjogren syndrome in 9 patients $(16.7 \%)$ and SLE in 3 patients (5.5\%). Six patients remained classified as IPAF (11.1\%). Among the Rheumatology patients we followed-up in the same period, autoimmune myositis had the highest prevalence of ILD as initial manifestation (63.6\%), followed by Sjogren syndrome (20.5\%), systemic sclerosis $(20.0 \%)$, RA $(3.4 \%)$, and SLE (3.3\%). 2) Patients with initial ILD were all firstly evaluated by the Pulmonologist and the main reasons for Rheumatology referral were positivity for one or more autoantibodies (57.4\%), mainly ANA $\geq 1: 320$, and joint pain $(29.6 \%)$. Thirty-six patients $(66.7 \%)$ received steroid and/or immunosuppressive therapy in the six months before the first Rheumatology visit to relieve respiratory symptoms. Twenty of these patients $(58.8 \%)$ had rheumatic manifestations during steroid tapering. ILD CT patterns were NSIP (25 patients, 52.1\%), UIP (18 patients, $33.4 \%$ ), and organizing pneumonia (5 patients, $9.3 \%$ ). In four patients $(4.5 \%)$, autoantibodies became positive during the follow-up. The final diagnosis of CTDor RA-ILD was made after a median period of 16.5 (6-39) months from the clinical onset. At the time of diagnosis, average FVC was $90.4 \pm 18.7 \%$ of predicted, DLCO $55.4 \pm 20.2 \%$ and the median GAP index was 3 (2-3). During the median follow-up of 48 months, eight patients (14.8\%) had a decline in DLCO of $\geq 15 \%$ predicted and/or a decline in FVC of $\geq 10 \%$ despite immunosuppressive drugs. Nine patients $(17 \%)$ died and six of these patients $(11.1 \%)$ for causes related to ILD. Conclusion: In our study population, the prevalence of ILD as initial manifestation of CTD or RA was $12.6 \%$. Autoimmune myositis, systemic sclerosis and Sjogren syndrome were the most frequent diagnosis. As our data confirmed, ILD is a major cause of death in patients with systemic autoimmune diseases and can progress despite immunosuppression [1]. Furthermore, clinical features may become evident even months after the disease onset. A multidisciplinary evaluation is therefore essential, not only at the time of diagnosis but also during the follow-up [2].

References:

[1] A. Fischer et al. Progressive fibrosing interstitial lung disease associated with systemic autoimmune diseases. Clin Rheum (2019); 38:2673-81

[2] F. Furini, et al. The role of the Multidisciplinary Evaluation of Interstitial Lung Diseases: Systematic Literature Review of the Current Evidence and Future Perspectives. Front Med (2019); 6:246

Disclosure of Interests: None declared

DOI: 10.1136/annrheumdis-2020-eular.4645

\section{FRI0642-HPR BARRIERS AND FACILITATORS FOR PHYSICAL ACTIVITY ARE MAINLY RELATEDTO PSYCHOLOGICAL ISSUES IN INFLAMMATORY ARTHRITIS - A MIXED- METHODS STUDY OF 66 PATIENTS IN FRANCE.}

T. Davergne ${ }^{1}$, R. H. $\mathrm{Moe}^{2}$, B. Fautrel ${ }^{1}$, L. Gossec ${ }^{1} .{ }^{1}$ Sorbonne University Assistance Publique Hopitaux de Paris, Paris, France, ${ }^{2}$ Dept. of Rheumatology, Diakonhjemmet Hospital, Oslo, Norway

Background: Patients with inflammatory arthritis (IA) like (ankylosing spondylitis (AS), rheumatoid arthritis (RA), and psoriatic arthritis (PsA) are more prone to physical inactivity but derive specific benefits from regular physical activity (PA)
(1). Barriers and facilitators to PA are key elements that have not yet been well described.

Objectives: To assess if barriers and facilitators for PA in patients with IA are mostly related to disease, psychological, social or environmental factors.

Methods: A list of the most important barriers and facilitators was derived from a systematic review of barriers and facilitators to PA in rheumatoid arthritis (2). This list was assessed for face validity by 11 experts from Rheumatology or physiotherapy then tested by 10 patients through structured interview.

The list of barriers and facilitators was completed in a binary way: "barriers or facilitators are relevant to me" yes or no, for 66 patients in a monocentric, cross-sectional study. Then, patients assessed the level of each barrier or facilitator on a 0-10 scale. Statistics were descriptive. There was no imputation of missing data. Results: The study included 66 patients (27 axial spondyloarthritis, 26 rheumatoid arthritis, 13 psoriatic arthritis), mean age 52.0 (standard deviation (SD) 16.6) years, mean disease duration 14.3 (SD 11.7) years, 53\% women. Disease activity was moderate (mean DAS28 2.1 (SD 1.1), mean BASDAI 2.8 (SD 1.4)), and $75.4 \%$ received a biologic. The main factors described by patients were related to the knowledge of the benefits of PA and symptoms (table 1). Psychological factors were more reported and social factors less reported as influential for PA.

Table 1. Barriers and facilitators for physical activity reported by patients with inflammatory arthritis.

\begin{tabular}{|c|c|c|c|c|}
\hline Barriers or facilitators & Categorie & lodifiable & $\begin{array}{l}\mathrm{N}(\%) \text { report- } \\
\text { ing this barrier } \\
\text { or facilitator }\end{array}$ & $\begin{array}{l}\text { Level of patients } \\
\text { reporting this } \\
\text { item }(0-10) \text { (mean } \\
(S D))\end{array}$ \\
\hline $\begin{array}{l}\text { Knowledge of benefits of physical } \\
\text { activity for health }\end{array}$ & Psych & Yes & $49(78)$ & 6.6 \\
\hline $\begin{array}{l}\text { Knowledge of benefits of physical } \\
\text { activity for mood }\end{array}$ & Psych & Yes & $47(75)$ & $6.8(3.4)$ \\
\hline $\begin{array}{l}\text { Level of symptoms (pain, fatigue, } \\
\text { lack of mobility) }\end{array}$ & Phy & Yes & $44(69)$ & $5.7(2.8)$ \\
\hline $\begin{array}{l}\text { External reminders (eg: from health } \\
\text { professionals, calendars...) }\end{array}$ & Soc & Yes & $36(57)$ & $6.2(3.1)$ \\
\hline $\begin{array}{l}\text { Presence or absence of activity } \\
\text { facilities (ex: green area for walking, } \\
\text { gym ...) }\end{array}$ & Evmt & No & $34(56)$ & $6.3(3.7)$ \\
\hline Lack of motivation & Psych & Yes & $34(55)$ & $5.7(3.2)$ \\
\hline Weather conditions & Evmt & No & $33(52)$ & $5.7(3.2)$ \\
\hline Confidence on how to exercise safely & Psych & Yes & $31(49)$ & $6.0(2.6)$ \\
\hline $\begin{array}{l}\text { Contact and proximity with others } \\
\text { during physical activity }\end{array}$ & Soc & No & $29(47)$ & $6.1(3.7)$ \\
\hline $\begin{array}{l}\text { Presence or absence of support from } \\
\text { others (friends, family) }\end{array}$ & Soc & No & $26(42)$ & $6.5(3.9)$ \\
\hline Lack of time & Evmt & No & $35(40)$ & $5.4(3.4)$ \\
\hline $\begin{array}{l}\text { Presence or absence of support } \\
\text { and/or advice from healthcare } \\
\text { professionals }\end{array}$ & Soc & Yes & $25(40)$ & $6.0(3.7)$ \\
\hline $\begin{array}{l}\text { A belief that physical activity will } \\
\text { make symptoms worse }\end{array}$ & Psych & Yes & $17(27)$ & $4.8(3.3)$ \\
\hline $\begin{array}{l}\text { Lack of knowledge on which exer- } \\
\text { cises to do and how much }\end{array}$ & Psych & Yes & $17(27)$ & $4.7(3.0)$ \\
\hline
\end{tabular}

Psych $=$ psychological, Evmt $=$ environmental, Phy $=$ physical, Soc $=$ social

Conclusion: The main factors that influence PA in patients with IA were mostly related to psychological aspects, and could be modifiable. The role of health professionals supporting patient PA is key. Interventions should be further explored to meet these important barriers and facilitators.

References:

[1] O'Dwyer T, Physical activity guidelines: is the message getting through to adults with rheumatic conditions? Rheumatol U K. 2014

[2] Davergne T, Thu0716-Hpr Major Barriers and Facilitators to Physical Activity in Rheumatoid Arthritis Are Related to Physical and Psychological Health, Setting and Social Environmental Factors: A Systematic Literature Review. Ann Rheum Dis. 2019

Disclosure of Interests: Thomas Davergne: None declared, Rikke Helene Moe: None declared, Bruno Fautrel Grant/research support from: AbbVie, Lilly, MSD, Pfizer, Consultant of: AbbVie, Biogen, BMS, Boehringer Ingelheim, Celgene, Lilly, Janssen, Medac MSD France, Nordic Pharma, Novartis, Pfizer, Roche, Sanofi Aventis, SOBI and UCB, Laure Gossec Grant/research support from: Lilly, Mylan, Pfizer, Sandoz, Consultant of: AbbVie, Amgen, Biogen, Celgene, Janssen, Lilly, Novartis, Pfizer, Sandoz, Sanofi-Aventis, UCB DOI: 10.1136/annrheumdis-2020-eular.3078

\section{FRI0643-HPR CARDIOVASCULAR DISEASE AMONG PATIENTS WITH RHEUMATOID ARTHRITIS COMPARED WITH THOSE WITH OSTEOARTHRITIS}

F. Wang ${ }^{1}$, B. Mukeriji ${ }^{1}$, R. Markert ${ }^{2}$, V. Mukerji ${ }^{3} .{ }^{1}$ Dayton Veterans Administration Medical Center, Dayton, United States of America; ${ }^{2}$ Wright State University 